\title{
MULTIPLICANDO A EDUCAÇÃO EMPREENDEDORA NAS ESCOLAS PÚBLICAS: O CASO DO "CURSO DE ATUALIZAÇÃO EM PIONERISMO E EDUCAÇÃO EMPREENDEDORA" DA UNIVERSIDADE DE SÃO PAULO
}

Caroline Gonçalves ${ }^{1}$

Alexandre Saes ${ }^{2}$

Jacques Marcovitch ${ }^{2}$

${ }^{1}$ Câmpus do Pantanal / Universidade Federal de Mato Grosso do Sul

${ }^{2}$ Universidade de São Paulo 


\section{MULTIPLICANDO A EDUCAÇÃO EMPREENDEDORA NAS ESCOLAS PÚBLICAS: O CASO DO "CURSO DE ATUALIZAÇÃO EM PIONEIRISMO E EDUCAÇÃO EMPREENDEDORA" DA UNIVERSIDADE DE SÃO PAULO}

Resumo: O presente artigo busca contar o caso do "Curso de atualização em pioneirismo e educação empreendedora" realizado por docentes e colaboradores da Universidade de São Paulo, voltado à formação e atualização de professores de escolas da rede pública de ensino. $\mathrm{O}$ artigo apresenta as metodologias utilizadas para as etapas presenciais e à distância do curso, e os principais resultados obtidos. Esta experiência culminou com a homologação do curso junto à Escola de Formação e Aperfeiçoamento dos Professores do Estado de São Paulo "Paulo Renato Costa Souza", vinculada à Secretaria de Educação do Estado de São Paulo, possibilitando aos participantes certificação necessária à pontuação para evolução funcional.

Palavras-chave: Educação empreendedora; Empreendedorismo; Pioneirismo empresarial; Curso de atualização para educadores. 


\section{INTRODUÇÃO}

Este artigo visa apresentar o caso de ensino do "I Curso de Atualização em Pioneirismo e Educação Empreendedora”, originado na cidade de São Paulo, entre os meses de maio e agosto de 2017. O curso contou com a participação de educadores e gestores educacionais de diferentes localidades do país, que desenvolveram projetos modelo para aplicação dos conteúdos assimilados ao longo do processo de aprendizagem. Neste relato, procura-se consolidar e apresentar os principais aspectos metodológicos do curso, os objetivos e metas iniciais e as realizações obtidas por meio desta vivência, possibilitando assim tanto uma auto-avaliação do curso pelos próprios autores, bem como uma reflexão crítica dos leitores, diante da possibilidade de extração de ideias e caminhos que possibilitem a criação e/ou replicação de um curso de tal natureza.

O "I Curso de Atualização em Pioneirismo e Educação Empreendedora" faz parte da iniciativa "Pioneiros na Sala de Aula", que contou com a realização anterior a este dos cursos: "I Curso de Difusão - Pioneirismo Empresarial e a Construção do Século XXI", realizado em 30 e 31 de julho de 2013 na Biblioteca Brasiliana Guita e José Mindlin.; "II Curso de Difusão - Pioneirismo Empresarial e a Construção do Século XXI: as Regiões Norte e Nordeste do Brasil" realizado em 30 e 31 de julho de 2014 na FEA/USP; "III Curso de Difusão - Pioneirismo Empresarial e a Construção do Século XXI: O Brasil Reencontra os Pioneiros de São Paulo", realizado em 29 e 30 de julho de 2015, na FEA/USP; e "IV Curso de Difusão - Pioneirismo Empresarial e a Construção do Século XXI:Capacitação de Professores e novas práticas", realizado em 27 e 28 de julho de 2016 no Museu da Imigração do Estado de São Paulo. A iniciativa "Pioneiros em Sala de Aula", por sua vez, integra o projeto "Pioneiros e Empreendedores: A Saga do Desenvolvimento no Brasil" que teve início no ano de $2001^{1}$.

O objetivo geral do "I Curso de Atualização em Pioneirismo e Educação Empreendedora" concentrou-se em proporcionar a compreensão do pioneirismo empresarial e relacioná-lo com as tendências geracionais na atualidade. Foi delineado conforme os parâmetros estabelecidos pela Lei $15.693 / 2015^{2}$, que cria o Plano Estadual de Educação Empreendedora. O curso foi aprovado em no dia 09 de Março de 2017, conforme Processo

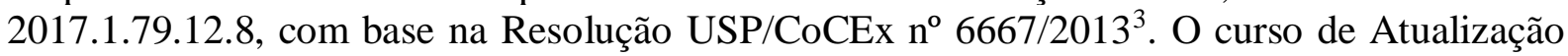
foi certificado pela Universidade de São Paulo, e oferecido sem ônus para os participantes matriculados.

Os objetivos específicos do curso visaram, por meio da análise da trajetória e das ações dos Pioneiros, tornar os participantes aptos a: (a) traçar as características pedagógicas do pioneirismo e do empreendedorismo e suas repercussões contemporâneas; (b) elencar as habilidades necessárias para o desenvolvimento de ações empreendedoras e as possibilidades

\footnotetext{
1 "Pioneiros e Empreendedores: A Saga do Desenvolvimento no Brasil" é um projeto de extensão universitária da USP, iniciado em 2001, como forma de reunir material e produzir conhecimento sobre a história empresarial brasileira.”, Para saber mais sobre o projeto Pioneiros e Empreendedores: <https://usp.br/pioneiros/n/>.

${ }^{2}$ Disponível em <http://www.al.sp.gov.br/repositorio/legislacao/lei/2015/lei-15693-03.03.2015.html>. Acesso em 04 Mar 2018.

${ }^{3}$ Disponível em <http://www.leginf.usp.br/?resolucao=resolucao-cocex-6667-de-19-de-dezembro-de-2013>. Acesso em 04 Mar 2018.
}

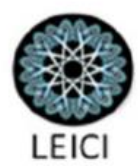


de desenvolvimento das mesmas em sala de aula; e (c) compreender as possibilidades de trabalho com a pedagogia empreendedora, por meio da criação de um projeto empreendedor.

$\mathrm{Na}$ sequência a esta introdução, serão apresentadas as metodologias utilizadas para a consecução do curso, considerando conteúdo, materiais utilizados e descrição das etapas presenciais e à distância realizadas, além da descrição das metas e resultados obtidos.

\section{METODOLOGIA UTILIZADA}

O Curso foi realizado em formato semi-presencial totalizando 30 horas de duração, sendo 15 horas na etapa presencial e 15 horas na modalidade a distância. A etapa presencial aconteceu no Museu da Imigração do Estado de São Paulo. Para obtenção do Certificado de Conclusão, o participante deveria necessariamente participar do modulo presencial e concluir todas as atividades a distância, além de cumprir as demais atividades associadas e avaliar o curso.

Este curso está alinhado com os objetivos da Lei 15.693/2015 que cria o Plano Estadual de Educação Empreendedora para inserção do empreendedorismo nas escolas de ensino médio e escolas técnicas. O "Curso de Atualização em Pioneirismo e Educação Empreendedora" teve por fundamento a Resolução USP/CoCEx n ${ }^{\circ}$ 6667, de 19 de dezembro de 2013, que determina: O Curso de Atualização visa difundir o progresso do conhecimento em determinadas áreas ou disciplinas, terá, no mínimo, trinta horas de duração e será ministrado somente para alunos graduados. O coordenador geral do curso é o Prof. Alexandre Macchione Saes, docente da FEA/USP. Esta coordenação conta com a participação do Prof. Jacques Marcovitch, docente da FEA/USP, na condição de coordenador acadêmico, além de outros colaboradores.

\subsection{Público alvo, conteúdo e material didático}

O público alvo do curso foi composto por professores de todas as disciplinas das escolas integrais e/ou Fundamental II e Ensino Médio/Técnico do país, além de educadores de centros de memória, museus e instituições dedicadas a cultura do empreendedorismo e do pioneirismo empresarial. O curso foi iniciado com 212 interessados, teve 110 selecionados e 49 concluintes, sendo 34 deles aprovados ao término.

O conteúdo do curso teve como foco os temas: Pioneirismo e empreendedorismo, Pedagogia empreendedora, Habilidades do pensamento e desenvolvimento de processos mentais, e Mapas conceituais. Os mapas conceituais ${ }^{5}$. foram a ferramenta de apoio para o planejamento e elaboração dos projetos.

Foram apresentados aos participantes deste curso de atualização os conceitos que estruturam a exposição "Pioneiros \& Empreendedores" e o material de apoio desenvolvido, composto por Caderno do Professor e do Aluno, com conteúdo elaborado para posterior

\footnotetext{
${ }^{4}$ Disponível em <http://www.al.sp.gov.br/repositorio/legislacao/lei/2015/lei-15693-03.03.2015.html〉. Acesso em 04 Mar 2018.

5"Como fazer bons mapas conceituais? Estabelecendo parâmetros de referências e propondo atividades de treinamento" de Joana Guilares de Aguiar, Paulo Rogério Miranda Correia. http://revistas.if.usp.br/rbpec/article/viewFile/548/343.
} 
exploração dos temas e conceitos discutidos na exposição. Os materiais didáticos estão descritos em detalhe, na sequência, conforme a etapa do curso apresentada.

\subsection{Da etapa presencial}

Nos encontros presenciais, através de exercícios e estudos de caso, foram examinadas as ações e estratégias utilizadas pelos pioneiros brasileiros, para analisar as características da cultura empreendedora. Foram realizadas palestras com especialistas da área, jovens empreendedores e animadores de iniciativas de associativismo juvenil.

A etapa presencial foi o primeiro módulo do curso, com duração de 15 horas. As sessões do módulo presencial aconteceram nos dias 6 e 7 de maio (sábado e domingo) de 2017 das 09h00 às 18 h00 no Museu da Imigração do Estado de São Paulo.

Figura 1 - Participantes do Curso de Atualização em Pioneirismo e Educação Empreendedora

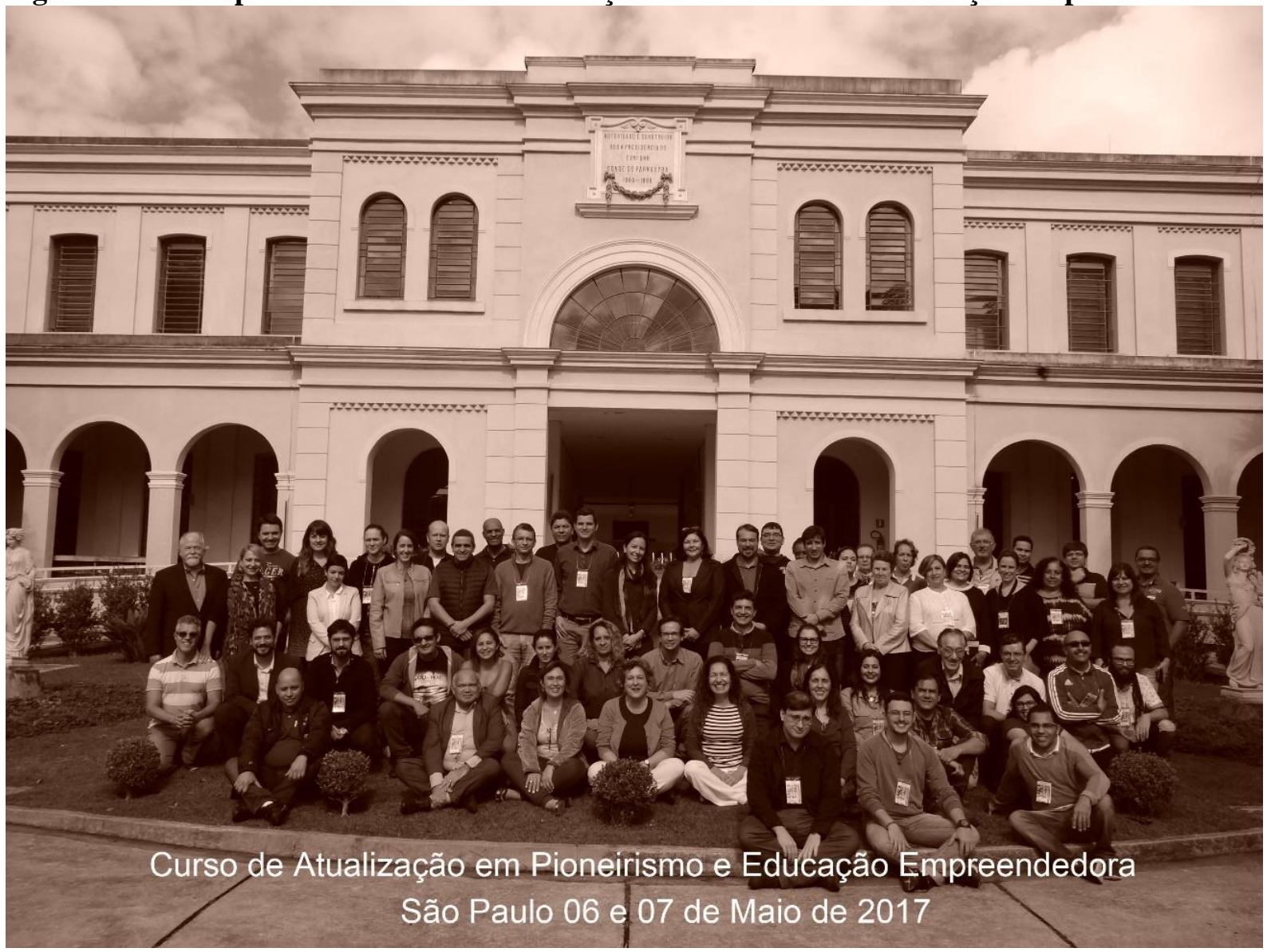

Fonte: os autores

Foram também realizadas visitas ao Museu da Imigração mediadas pela equipe do programa educativo. As visitas mediadas tiveram como objetivo levar os professores e estudantes a refletir sobre as ações dos pioneiros e criar conexões com a história do Brasil e os

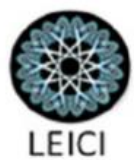


dias atuais. As visitas se encerraram com debates sobre os pioneiros, empreendedorismo e a contemporaneidade, além de oficinas de elaboração de projetos. definidas:

A programação detalhada da etapa presencial estava composta por quatro sessões, assim

$\underline{1^{\circ} \mathrm{Dia}-06 \text { de MAIO de } 2017}$

Sessão 1 - 09h00 - 11h00 - (2 horas): PIONEIRISMO E EDUCACÃO EMPREENDEDORA: PESQUISA, ENSINO E MUSEOLOGIA

- Apresentação do curso, das propostas de leitura, artigo, trabalho e ensaio biográfico.

- (Alexandre M. Saes e Jacques Marcovitch)

- Apresentação do site - biografias de alguns pioneiros paulistas - um dos vídeos de contextualização histórica. (Jacques Marcovitch)

- Apresentação do projeto Museológico "Pioneiros e Empreendedores" e dos seus conceitos estruturantes. (Maria Cristina de Oliveira Bruno)

- Relato das ações formativas realizadas desde 2010 no Rio de Janeiro, Ceará, Pernambuco e Amazonas. (Marina Sartori de Toledo)

- A implantação da Lei 15.693/2015, que cria o Plano Estadual de Educação Empreendedora. (Silvério Crestana)

Sessão 2 - 11h00 - 13h00 (2 horas) PIONEIRISMO EM SÃO PAULO

- Palestra Pioneirismo em São Paulo

- Debate a partir de uma questão-chave levantada pelos palestrantes aos participantes do curso. (Alexandre Saes e Jacques Marcovitch)

Sessão 3 - 14h00 - 16h00 (2 horas) IMIGRACÃO, EMPREENDEDORISMO E PIONEIRISMO

- Palestra: Imigração, empreendedorismo e pioneirismo. (Marilia Bonas)

Sessão 4 - 16h30 - 18h30 (2 horas) EDUCACÃO EMPREENDEDORA E MAPAS CONCEITUAIS

- Mapa conceitual na educação empreendedora. (Marina Sartori de Toledo)

- Munícipio empreendedor e Escola empreendedora. (Maria Lúcia Baltieri)

$\underline{2^{\circ} \text { Dia }-07 \text { de MAIO de } 2017}$

Sessão 5 - 09:00 - 11h00 (2 horas) PIONEIRISMO: ESTRATEGIAS E HABILIDADES

- Estratégias dos pioneiros e empreendedores e as habilidades do pensamento. (Jacques Marcovitch)

- Oficina com caderno educativo da exposição. Marina Sartori de Toledo 


\section{Sessão 6 - 11h00 - 13h00 (2 horas) PIONEIRISMO E ATITUDE EMPREENDEDORA}

- Palestra: Pioneirismo e atitude empreendedora. (Mara Sampaio)

- Encontro com jovens - Empreendedorismo juvenil elou Associativismo juvenil. (Tania Lima)

Sessão 7 - 14h00 - 16h00 (2 horas) PROJETO EMPREENDEDOR : MODELOS

- Proposta em grupo de um projeto empreendedor.

- Apresentação dos projetos e possibilidades de trabalho com os alunos. (Jacques Marcovitch, Mara Sampaio e Marina Sartori de Toledo)

Sessão 8 - 16h30 - 17h30 (1 hora) PIONEIRISMO COM UM VALOR PARA A SOCIEDADE

- Discussão com os participantes sobre as formas de delinear, aplicar e disseminar novas práticas para estimular, entre os jovens, ações inovadoras de transformação para desenvolver uma postura ativa diante da vida e da carreira, além de promover o pioneirismo como um valor para a sociedade. (Alexandre M. Saes, Jacques Marcovitch e Marina Sartori de Toledo)

Como conteúdos complementares às sessões foram disponibilizados aos participantes leituras, coletâneas de artigos e vídeos, conforme descrição a seguir:

\section{Leituras:}

- A musealização e a regionalidade (Maria Cristina Oliveira Bruno - USP)

- Pioneirismos brasileiros e o Estado de Pernambuco (George Cabral de Souza Universidade Federal de Pernambuco)

- Pioneirismos brasileiros e o Estado do Amazonas (Alfredo MR Lopes - Ensaísta)

- Os pioneiros e o Estado do Ceará (Gleudson Passos - UECE)

- Pioneiros e Empreendedores: relato da experiência educativa (Marina Sartori de Toledo - MLP)

- O Brasil Reencontra os Pioneiros: Textos e Contextos Regionais. (Coordenação: Jacques Marcovitch e Maria Cristina Oliveira Bruno. São Paulo: EDUSP, 2016.)

\section{Coletânea de artigos:}

- Pioneirismo empresarial e o ensino do empreendedorismo no Brasil. Coletânea dos melhores trabalhos sobre o tema, resultado dos ensaios apresentados por participantes do primeiro curso de difusão cultural, realizado em 2013, na Biblioteca Brasiliana Guita e José Mindlin - Universidade de São Paulo ${ }^{6}$.

Vídeos:

- Imigração e Pioneirismo empresarial no Brasil (Marília Bonas - Museu da Imigração)




- Pioneirismos brasileiros e o Estado de Pernambuco (George Cabral de Souza Universidade Federal de Pernambuco)

- Pioneirismos brasileiros e o Estado do Amazonas (Alfredo MR Lopes - Ensaísta)

- Os pioneiros e o Estado do Ceará (Gleudson Passos - UECE)

- Pioneirismo Empresarial de São Paulo: fontes e conteúdos (Fernanda Carvalho Bureau de Recherche)

Acervo iconográfico:

- Imagens, apresentações e vídeos relacionados a 24 pioneiros brasileiros ${ }^{7}$.

\subsection{Da etapa à distância}

A etapa à distância do curso teve duração de 15 horas. O ritmo e andamento do módulo à distância foi de livre escolha dos participantes, aconselhando-se uma carga de duas a três sessões semanais de dedicação ao módulo a distância.Sendo disponibilizada no início do curso, recomendou-se que as atividades à distância fossem feitas antes da atividade presencial, devendo necessariamente ser concluídas até o dia 17de Julho de 2017.

O Website onde se realizou o curso é o <https://www.usp.br/pioneirosead/index.php> e sua interface com o usuário apresenta-se conforme Figura 2: 
Figura 2 - Website do curso

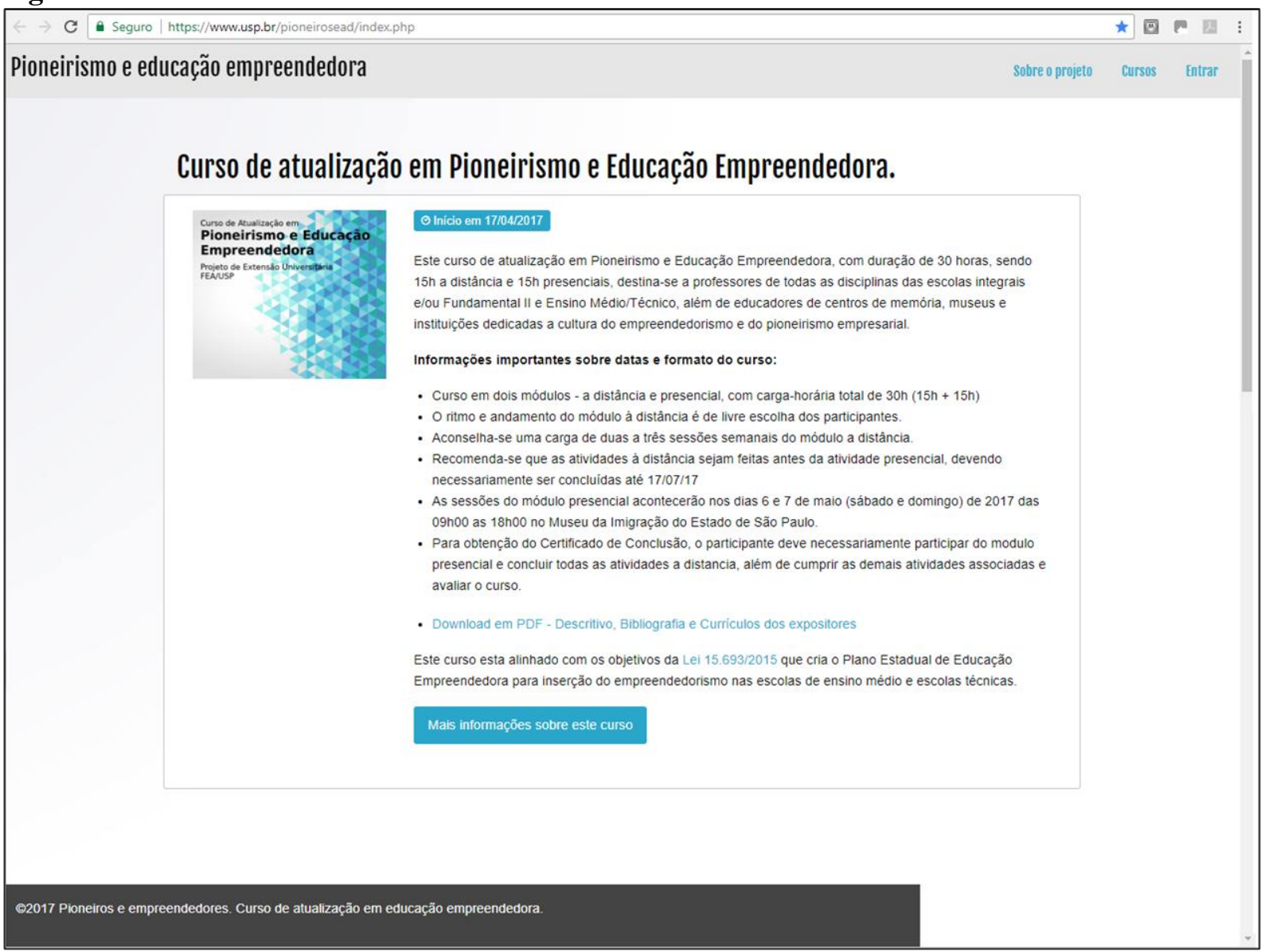

Fonte: os autores

A estrutura básica do módulo à distância estava composta por 08 sessões, assim divididas:

\section{Sessão 1 - História Econômica e História Empresarial (1 hora)}

Conteúdos:

Leituras: FAUSTO, Boris. História Concisa do Brasil. São Paulo: Edusp, 2001.

SAES, Flávio A.M; SAES, Alexandre M. História Econômica Geral. São Paulo: Saraiva, 2015

Vídeo: História Econômica do Brasil - Prof. Alexandre Macchione Saes (FEA/USP).

Questões:

a) Quais foram as inquietações e os dilemas espelhados na controvérsia "Eugênio Gudin versus Roberto Simonsen"?; b) Como se traduzem esses dilemas e inquietações na aurora do 
século XXI?; c) Quais são as referências bibliográficas em História Econômica e História de Empresas que mereceriam ser contempladas nos componentes curriculares dos cursos de História do Brasil?

\section{Sessão 2 - Pioneiros Brasileiros I (2 horas)}

Conteúdos:

Leitura: MARCOVITCH, J. Pioneiros e Empreendedores. Vol. I. São Paulo: Edusp, 2003, Cap. 4: Francisco Matarazzo.

Vídeo: Francesco Matarazzo: a reinvenção da acumulação capitalista - Prof. José de Souza Martins (FFLCH/USP)

\section{Questões:}

a) Quais são os principais marcos de referência na trajetória de Francesco Matarazzo?; b) Como foram as crises políticas, econômicas e sociais enfrentadas por ele?; c) Quais são as principais lições legadas por este pioneiro para a construção do futuro?

\section{Sessão 3 - Pioneiros Brasileiros II (2 horas)}

\section{Conteúdos:}

Leitura: MARCOVITCH, J. Pioneiros e Empreendedores. Vol. I. São Paulo: Edusp, 2003. Cap. 5: Ramos de Azevedo.

Vídeo: Ramos de Azevedo - Profa. Beatriz Siqueira Bueno (FAU/USP)

\section{Questões:}

a) Quais são os principais marcos de referência na trajetória do Ramos de Azevedo?; b) Como foram as crises políticas, econômicas e sociais enfrentadas por ele ?; c) Quais são as principais lições legadas por este pioneiro para a construção do futuro?

\section{Sessão 4 - Pioneiros Brasileiros III (2 horas)}

Conteúdos:

Leitura: MARCOVITCH, J. Pioneiros e Empreendedores. Vol. I, São Paulo: Edusp, 2003. Cap. 6: Jorge Street.

Vídeo: Jorge Street: A fábrica do sonho - Profa. Palmira Petratti (Unesp)

\section{Questões:}

a) Quais são os principais marcos de referência na trajetória de Jorge Street? ; b) Como foram as crises políticas, econômicas e sociais enfrentadas por ele?; c) Quais são as principais lições legadas pelo pioneiro para a construção do futuro? 


\section{Sessão 5 - Pioneiros Brasileiros IV (2 horas)}

Conteúdos:

Leitura: MARCOVITCH, J. Pioneiros e Empreendedores. Vol. I, São Paulo: Edusp, 2003. Cap. 7: Roberto Simonsen.

Vídeo: Roberto Simonsen: a reinvenção das relações de trabalho - Prof. José de Souza Martins (FFLCH-USP)

\section{Questões:}

a) Quais são os principais marcos de referência na trajetória de Roberto Simonsen?; b) Como foram as crises políticas, econômicas e sociais enfrentadas por ele?; c) Como o pensamento econômico e a ação empresarial de Roberto Simonsen poderiam ser melhor inseridos nos cursos de História do Brasil?

\section{Sessão 6 - Pioneiros Brasileiros V (2 horas)}

\section{Conteúdos:}

Leitura: MARCOVITCH, J. Pioneiros e Empreendedores. Vol. I. São Paulo: Edusp, 2003. Cap. 8: Julio Mesquita.

Vídeo: Júlio Mesquita: fundador do jornalismo moderno no Brasil - Dr. Jorge Caldeira (Academia Paulista de Letras)

\section{Questões:}

a) Quais são os principais marcos de referência na trajetória de Julio Mesquita?; b) Como foram as crises políticas, econômicas e sociais enfrentadas por ele?; c) Quais são as principais lições legadas por este pioneiro para a construção do futuro?

\section{Sessão 7 - Pioneiros Brasileiros VI (2 horas)}

Conteúdos:

Leituras: MARCOVITCH, J. Pioneiros e Empreendedores. Vol. II. São Paulo: Edusp, 2005. Cap. 3: Luiz de Queiroz. O legado de Luiz e Ermelinda de Souza Queiroz.

Vídeo: Luiz de Queiroz: Os passos do saber - Marly Therezinha Germano Perecin (USP e Academia Piracicabana de Letras)

\section{Questões:}

a) Quais são os principais marcos de referência na trajetória de Luiz de Souza Queiroz?; b) Como foram as crises políticas, econômicas e sociais enfrentadas por ele?; c) Quais são as principais lições legadas por este pioneiro para a construção do futuro? 


\section{Sessão 8 - Pioneiros Brasileiros VII (2 horas)}

Conteúdos:

Leitura: MARCOVITCH, J. Pioneiros e Empreendedores. Vol. II. São Paulo: Edusp, 2005, Cap. 8: José Ermírio de Moares.

Vídeo: José e Antônio Ermírio de Moraes - André Ermírio de M. Macedo (Memória Votorantim)

\section{Questões:}

a) Quais são os principais marcos de referência na trajetória de José Ermírio de Moraes?; b) Como foram as crises políticas, econômicas e sociais enfrentadas por ele?; c) Quais são as principais lições legadas por este pioneiro para a construção do futuro?

\section{Questões a serem respondidas ao término das 8 sessões de Ensino a Distância:}

a) Que lições podem ser extraídas da trajetória dos pioneiros estudados para a formação das gerações do século XXI?

b) Quais foram os valores e competências que contribuíram para que essas adversidades fossem superadas?

c) Com base nos estudos realizados, quais são os conteúdos e as metodologias que melhor contribuem para promover a pedagogia empreendedora e a cultura do pioneirismo na sala de aula e na escola?

\section{Ensaio: Empreendedorismo hoje}

Pesquisa de campo sobre um empreendedor do bairro em que vive o educador/professor participante do curso. Inclua: sua biografia, as características que o tornaram um empreendedor, sua trajetória e o seu perfil. Descreva este empreendedor. Compare os seus valores e competências com um ou mais dos pioneiros estudados.

\subsection{Da pesquisa de campo}

$\mathrm{Na}$ etapa de pesquisa de campo, os participantes pesquisaram a trajetória de empreendedores atuais de suas regiões, ou atividades empreendedoras a partir da localidade do professor/educador, município ou bairro e das relações entre a escola e seu entorno.

A partir de leituras complementares oferecidas, os participantes puderam escrever um ensaio sobre um dos seguintes tópicos: aplicação das práticas de empreendedorismo na sala de aula, práticas de cultura empreendedora na escola, práticas de cultura empreendedora no município, pioneirismo e projeto empreendedor, empreendedorismo e projeto de vida. 


\section{RESUlTADOS: METAS PROPOSTAS, ATINGIDAS E OUTRAS REALIZAÇÕES}

\subsection{Das metas gerais atingidas}

As metas atingidas por esse projeto se resumem em:

- Formação de professores na metodologia proposta pelo Projeto Educativo "Pioneiros \& Empreendedores";

- Desenvolvimento de projetos empreendedores pelos alunos, por meio de uma parceria Escola - Universidade - Exposição, compreendendo:

a. Preparação dos participantes sobre o tema "Pioneirismo e Empreendedorismo";

b. Visita das classes dos professores/participantes do curso de formação à exposição;

c. Oficina de projeto empreendedor na exposição, para esboço do projeto;

d. Desenvolvimento do projeto empreendedor em sala de aula;

e. Envio dos projetos propostos e avaliações dos participantes para a equipe coordenadora.

\subsection{Do pioneirismo e o recorte histórico.}

A análise das ações e estratégias dos pioneiros de um período histórico - constantes no Caderno do Aluno - tornaram possíveis o levantamento das características comuns e habilidades necessárias para desenvolver essas estratégias. Para cada tópico foram indicadas referências bibliográficas e material audiovisual, além de interação via exercícios sobre o tema.

\subsection{Do Projeto Modelo}

Por meio do diagnóstico das atividades empreendedoras de um bairro ou região do país, e das relações entre escola, saúde e cultura, foi possível preparar um projeto modelo de ações empreendedoras.

\subsection{Sobre o empreendedorismo hoje}

A pesquisa de campo sobre um empreendedor do bairro em que vive o professor/ participante do curso pôde proporcionar a este participante o conhecimento sobre sua biografia, as características que o tornaram um empreendedor, sua trajetória. Este levantamento culmunou na escrita de seu perfil, para entrega à coordenação do curso.

3.5 Ensaio de conclusão do curso de atualização e formação do livro "Pioneirismo e educação empreendedora: projetos e iniciativas"

Os participantes do curso puderam redigir um artigo sobre um dos seguintes tópicos: ensaio sobre o empreendedor local estudado, empreendedorismo e contemporaneidade, 
pioneirismo e projeto empreendedor, empreendedorismo e projeto de vida.

Em cerimônia realizada no dia 17 de Agosto de 2017 na FEA/USP foram selecionados alguns trabalhos para apresentação e entrega de certificados para os participantes.Os melhores projetos desenvolvidos no âmbito do curso "Pioneirismo e Educação Empreendedora" foram publicados no livro: Jacques Marcovitch, Alexandre Macchione Saes (orgs). Pioneirismo e educação empreendedora: projetos e iniciativas. São Paulo: Com-Arte, 2018. A edição impressa é distribuída pela EDUSP e há também uma versão em formato eletrônico ${ }^{8}$.

A coletânea foi organizada em cinco partes, que buscaram reunir por afinidade temática os projetos apresentados ao final do curso "Pioneirismo e Educação Empreendedora", levando em conta os espaços e formas de disseminação de uma educação empreendedora. Afinal, esta não deve ficar circunscrita dentro das salas de aula, mas podem ser levadas para museus, ONGs e, acima de tudo, na relação dos alunos com suas comunidades.

A primeira parte do livro, "Empreendedorismo, Política Pública e Modelos de Formação de Educadores", abarca projetos cujo olhar para a educação empreendedora se efetiva a partir das instituições difusoras deste inovador modelo de aprendizagem, isto é, a partir de políticas públicas municipais, como também de experiências de cursos voltados para a formação de educadores.

A segunda parte, "Empreendedorismo e Inovação", por sua vez, relata as experiências presentes no Inova Paula Souza, importante projeto desenvolvido pelo Centro Paula Souza, no intuito de disseminar o ensino por meio de laboratórios de empreendedorismo e inovação. "Difusão Cultural", terceira parte da obra, ilustra as mais diversas possibilidades de implementação do ensino empreendedor para além do espaço mais tradicional da sala de aula, como os museus, exposições e até mesmo os jogos digitais.

A parte quatro, "Da Escola para a Comunidade - Da Comunidade para a Escola", é dedicada aos projetos que demonstram as valiosas experiências da relação entre a aprendizagem para além dos muros da escola, encontrando na comunidade não somente um objeto de intervenção e apropriação do conhecimento, mas também como exemplo das práticas e experiências reais para serem reapropriadas dentro de sala de aula.

Finalmente, a parte cinco da coletânea, "Incentivando Atividades Empreendedoras", sintetiza talvez o mais valioso resultado da difusão de uma educação empreendedora, a possibilidade de fomentar nos alunos não somente a autonomia, o pensamento crítico e a proatividade no processo de aprendizagem, mas também a possibilidade de estimular novas formas de interação dos jovens com os desafios do futuro.

\subsection{Apreciação crítica dos responsáveis pelo curso}

O curso Pioneirismo e Educação Empreendedora cumpriu de maneira bastante satisfatória com seus objetivos. Com a participação de um número significativo de interessados, especialmente considerando ter sido sua primeira edição, o curso permitiu uma profícua interação entre os professores mediadores e os educadores das escolas públicas. A combinação

${ }^{8}$ O e-livro é acessível gratuitamente no link: http://www.livrosabertos.sibi.usp.br/portaldelivrosUSP/catalog/book/192
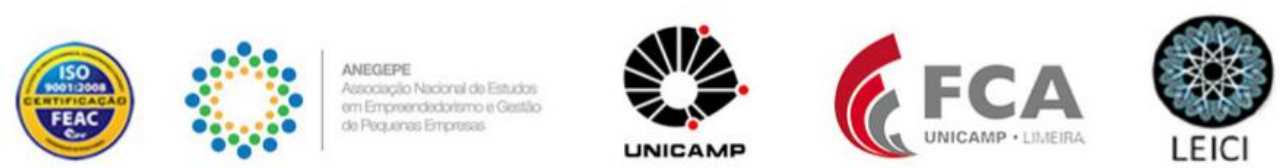
de atividades a distância com atividades presenciais também se mostrou bastante positiva, preparando os participantes com o material antes dos encontros presenciais.

Os projetos modelos, de educação empreendedora, expostos no encontro de encerramento, demonstraram a grande capacidade criativa e empreendedora dos professores na elaboração de estratégias inovadoras de ensino.

Vale lembrar que este curso está alinhado com os objetivos da Lei 15.693/2015 que cria o Plano Estadual de Educação Empreendedora para inserção do empreendedorismo nas escolas de ensino médio e escolas técnicas. http://www.al.sp.gov.br/repositorio/legislacao/lei/2015/lei15693-03.03.2015.html

\subsection{Síntese da avaliação do curso pelos participantes}

Efetuou-se após o curso, a "Avaliação PRCEU dos participantes", aplicada e tabulada pela Pró Reitoria de Cultura e Extensão da USP. Os participantes eram convidados a responder, após cada etapa do curso, a um questionário sobre o módulo/disciplina aplicada, destacando aspectos de (a) Conteúdo, (b)Avaliação, (c) Pessoal (d) Atendimento do pessoal de apoio online e (e) Curso, revelando resultados conforme exemplo demonstrado na Tabela 1:

Tabela 1 - Exemplo de avaliação de uma disciplina do curso

\begin{tabular}{|c|c|c|c|c|}
\hline \multicolumn{5}{|c|}{$\begin{array}{l}\text { Avaliação da disciplina: Presencial } 8 \text { - Pioneirismo como um valor para a sociedade } \\
\text { Turma: } 76434 \\
\text { Total de alunos matriculados: } 49 \\
\text { Total de questionários respondidos: } 29\end{array}$} \\
\hline Conteúdo & Avaliação & Pessoal & $\begin{array}{l}\text { Atendimento do } \\
\text { Pessoal de Apoio } \\
\text { Online }\end{array}$ & $\overline{\mathrm{Cu}}$ \\
\hline $\begin{array}{l}\text { 1. Acesso às } \\
\text { informações } \\
\text { necessárias sobre a } \\
\text { disciplina } \\
\text { (programa, } \\
\text { bibliografia, de } \\
\text { critérios } \\
\text { avaliação } \\
\text { cronograma). } \\
\text { Péssimo: } 0,00 \% \\
\text { Ruim: } 0,00 \% \\
\text { Regular: } 0,00 \% \\
\text { Bom: } 17,24 \% \\
\text { Ótimo: } 82,75 \% \\
\text { 2. Adequação do } \\
\text { conteúdo da } \\
\text { disciplina à carga } \\
\text { horária empregada. } \\
\text { Péssimo: } 0,00 \%\end{array}$ & 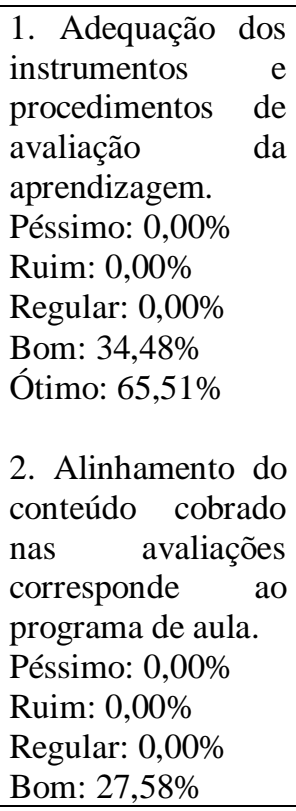 & \begin{tabular}{l} 
1. Seu grau de \\
conhecimento \\
anterior para \\
acompanhar a \\
disciplina. \\
Péssimo: $0,00 \%$ \\
Ruim: 3,44\% \\
Regular: 3,44\% \\
Bom: 55,17\% \\
Ótimo: 37,93\% \\
\multicolumn{1}{c}{ Grau de } \\
2. o \\
dificuldade para o \\
acompanhamento \\
da disciplina. \\
Péssimo: $0,00 \%$ \\
Ruim: $0,00 \%$ \\
Regular: $6,89 \%$ \\
Bom: 44,82\% \\
Ótimo: 48,27\%
\end{tabular} & $\begin{array}{l}\text { 1. Cortês } \\
\text { atencioso } \\
\text { Não se aplica: } \\
\text { 6,89\% } \\
\text { Péssimo: } 0,00 \% \\
\text { Ruim: } 0,00 \% \\
\text { Regular: } 0,00 \% \\
\text { Bom: } 20,68 \% \\
\text { Ótimo: } 72,41 \% \\
\text { 2. Eficiente e ágil } \\
\text { Não se aplica: } \\
\text { 6,89\% } \\
\text { Péssimo: } 0,00 \% \\
\text { Ruim: } 0,00 \% \\
\text { Regular: } 0,00 \% \\
\text { Bom: } 20,68 \% \\
\text { Ótimo: } 72,41 \%\end{array}$ & $\begin{array}{l}\text { 1. A duração do } \\
\text { curso foi adequada? } \\
\text { Péssimo: } 0,00 \% \\
\text { Ruim: } 0,00 \% \\
\text { Regular: } 3,44 \% \\
\text { Bom: } 34,48 \% \\
\text { Ótimo: } 62,06 \% \\
\quad \text { Houve boa } \\
\text { 2. e } \\
\text { continuidade } \\
\text { organização? } \\
\text { Péssimo: } 0,00 \% \\
\text { Ruim: } 0,00 \% \\
\text { Regular: } 0,00 \% \\
\text { Bom: } 37,93 \% \\
\text { Ótimo: } 62,06 \% \\
\text { 3. Qual seu nível de } \\
\text { satisfação com o } \\
\text { curso? }\end{array}$ \\
\hline
\end{tabular}




\begin{tabular}{|c|c|c|c|c|}
\hline 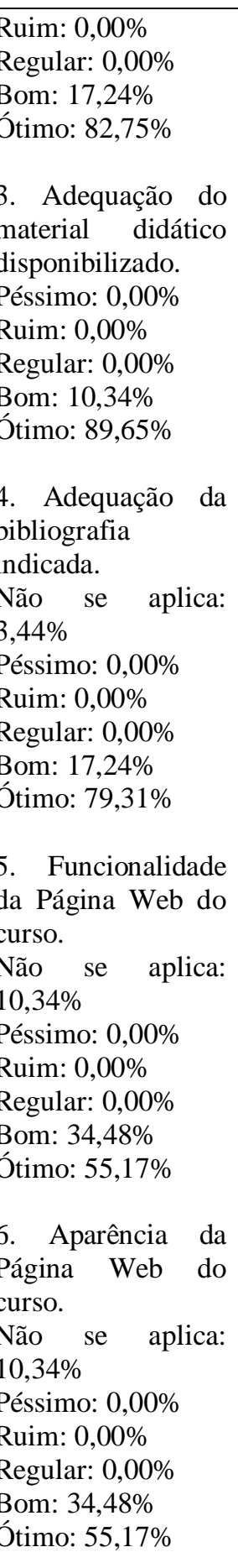 & $\begin{array}{l}\text { Ótimo: 72,41\% } \\
\text { 3. } \\
\text { disponível } \\
\text { resolução } \\
\text { avaliações. } \\
\text { Péssimo: } 0,00 \% \\
\text { Ruim: } 0,00 \% \\
\text { das } \\
\text { Regular: } 0,00 \% \\
\text { Bom: 31,03\% } \\
\text { Ótimo: } 68,96 \%\end{array}$ & 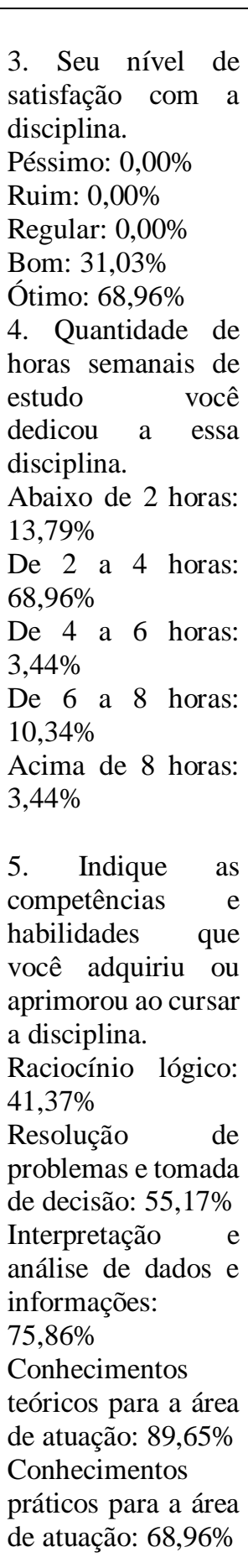 & $\begin{array}{l}\text { 3. Disponibilidade } \\
\text { de atendimento } \\
\text { Não se aplica: } \\
6,89 \% \\
\text { Péssimo: } 0,00 \% \\
\text { Ruim: } 0,00 \% \\
\text { Regular: } 0,00 \% \\
\text { Bom: } 17,24 \% \\
\text { Ótimo: } 75,86 \% \\
\text { 4. Tempo de espera, } \\
\text { tendo em vista os } \\
\text { serviços solicitados } \\
\text { Não se aplica: } \\
\text { 10,34\% } \\
\text { Péssimo: } 0,00 \% \\
\text { Ruim: } 0,00 \% \\
\text { Regular: } 0,00 \% \\
\text { Bom: } 20,68 \% \\
\text { Ótimo: } 68,96 \%\end{array}$ & $\begin{array}{l}\text { Péssimo: } 0,00 \% \\
\text { Ruim: } 0,00 \% \\
\text { Regular: } 0,00 \% \\
\text { Bom: } 24,13 \% \\
\text { Ótimo: } 75,86 \% \\
\text { 4. } \\
\text { recomendaria } \quad \text { Você } \\
\text { curso? } \\
\text { Sim: } 100,00 \% \\
\text { Não: } 0,00 \%\end{array}$ \\
\hline
\end{tabular}

Fonte: Os autores 
Unanimemente os participantes recomendam o curso e reforçaram o princípio que o desenvolvimento de uma educação empreendedora, como modelo inovador de aprendizagem. Adicionaram que esta formação requer educadores capacitados tanto por novas estratégias de ensino, quanto para a construção de uma nova relação entre aluno, professor e conhecimento.

\subsection{Homologação do curso}

No mês de Janeiro de 2018, foram enviados à Escola de Formação e Aperfeiçoamento dos Professores do Estado de São Paulo "Paulo Renato Costa Souza", vinculada à Secretaria de Educação do Estado de São Paulo, os seguintes documentos necessários à homologação do curso:

a) Oficio FEA/USP 03-2018 solicitando a EFAP a homologação do Curso "Pioneirismo e Educação Empreendedora"

b) Relatório Final de Homologação do Curso realizado de 17/04/17 a 15/08/17

c) Resultado da Avaliação dos Participantes aplicada e tabulada pela PRCEU/USP

Desta maneira, foram enviados à FEA/USP, em Fevereiro de 2018, pela Escola de Formação e Aperfeiçoamento dos Professores do Estado de São Paulo "Paulo Renato Costa Souza", os dados da Portaria de Homologação à FEA/USP, possibilitando que por meio do curso, os professores da rede pública estadual sejam pontuados para evolução funcional.

Assim, os cursistas habilitados terão a possibilidade de ter os seus certificados providenciados, constando, obrigatoriamente, no corpo do certificado, os dados da Portaria de Homologação EFAP ${ }^{9}$.

9 "Universidade de São Paulo / Faculdade de Economia, Administração e Contabilidade / FEA/USP - Universidade de São Paulo / Faculdade de Economia, Administração e Contabilidade / FEA/USP - Processo nº 058/3333/2017 - "Pioneirismo e Educação Empreendedora" - Professores / Educadores de Escolas Integrais, Ensino Fundamental II, Ensino Médio e Técnico - 17/04/2017 a 15/08/2017 - 30 horas - São Paulo / Museu da Imigração / São Paulo (presencial) e online. Portaria de Autorização EFAP de 10/08/2017, DOE 11/08/2017. Portaria de Homologação 16/02/2018, DOE 17/02/2018.". Esta Portaria foi publicada no dia 17 de Fevereiro de 2018, no Diário Oficial, Poder Executivo, Na Seção I, página 27, assim disposta: "Portaria do Coordenador, de 16-2-2018 Homologando, nos termos da Resolução SE 62/2017, o Curso de Atualização, "Pioneirismo e Educação Empreendedora", autorizado pela Portaria de Autorização Efap, de 10-8-2017, publicada no D.O. de 11-8-2017, realizado no período de 17-4- 2017 a 15-8-2017, com 30 horas em São Paulo - Museu da Imigração - São Paulo (presencial) e online.”. 


\section{BIBLIOGRAFIA}

FAUSTO, B. História Concisa do Brasil. São Paulo: Edusp,2001.

MARCOVITCH, J. Pioneiros e Empreendedores. Vol. I, São Paulo: Edusp, 2003.

Pioneiros e Empreendedores. Vol. II. São Paulo: Edusp, 2005.

MARCOVITCH, J.; SAES, A.M.(orgs.) Pioneirismo e educação empreendedora: projetos e iniciativas. São Paulo: Edusp, 2018.

SAES, F. A.M; SAES, A. M. História Econômica Geral. São Paulo: Saraiva, 2015. 